\title{
Selective Inhibition of Soluble TNF Using Xpro1595 Relieves Pain and Attenuates Cerulein-induced Pancreatic Pathology in Mice, With a Possible Link to Central Pain Processing
}

\author{
Rajasa Rhandi \\ VCU: Virginia Commonwealth University \\ Melissa Damon \\ VCU: Virginia Commonwealth University \\ Kirsty Dixon ( $\nabla$ kirsty.dixon@vcuhealth.org ) \\ VCU: Virginia Commonwealth University
}

\section{Research}

Keywords: Acute Pancreatitis, Cerulein, Mice, Inflammation, cytokines, TNF, TNFR1, Neuropathic pain Posted Date: December 16th, 2020

DOl: https://doi.org/10.21203/rs.3.rs-126759/v1

License: (c) (1) This work is licensed under a Creative Commons Attribution 4.0 International License. Read Full License 
1 Title: Selective inhibition of soluble TNF using XPro1595 relieves pain and attenuates cerulein-induced

2 pancreatic pathology in mice, with a possible link to central pain processing

3

4 Rajasa Rhandi a , Melissa Damon ${ }^{\text {a }}$, Kirsty J. Dixon *

5

6 Department of Surgery, Virginia Commonwealth University, 1101 E. Marshall St, Richmond VA 23298

$7 \quad{ }^{a}$ equal contributors

$8 *$ corresponding author

9

10 Running Title: XPro1595 improves pancreatitis disease outcomes

11 


\section{ABSTRACT}

Treatment of acute pancreatitis remains a challenge, with therapy focused on supportive care and treatment of the inciting etiology. Individuals with pancreatitis may experience severe upper abdominal pain, although pain mechanisms in patients with pancreatitis are incompletely understood and likely multifactorial, with possible pain processing occurring in the central nervous system, a process known to be associated with the upregulation of inflammatory cytokines. Inflammation plays a prominent role in the induction of acute pancreatitis, with the inflammatory cytokine tumor necrosis factor (TNF) both exacerbating cell death, pro-inflammatory signaling and edema, as well as promoting reparative and restorative mechanisms. This duality of function can be explained by different forms of the TNF ligand preferentially activating different receptor subtypes, whereby the uncleaved transmembrane form of the ligand (tmTNF) preferentially activates TNFR2 promoting restorative functions, but once cleaved the soluble form of TNF (solTNF) preferentially activates TNFR1 promoting detrimental pathology. For this reason, the traditional TNF inhibitors that inhibit both TNFR1 and TNFR2 have shown modest success in patients, but come with numerous side-effects, including immunological dysfunction and heart failure. Therefore, we sought to assess the effect of a novel selective inhibitor of solTNF (XPro1595) on pancreatic pathology and associated neuropathic pain in a mouse model of acute pancreatitis, and observe its effect on an area of the brain (the hippocampus) known to play a role in neuropathic pain processing. XPro1595 administration began after the initial peak in serum amylase to maximize clinical relevance. Administration of XPro1595 prevented pancreatic immune cell infiltration, that subsequently prevented tissue disruption and acinar cell death. These improvements in pathology were associated with a significant reduction in mechanical hypersensitivity (neuropathic pain). XPro1595 treatment also prevented an increase in hippocampal astrocyte reactivity, that may be associated with the prevention of neuropathic pain in this mouse model. Overall, we observed that selectively inhibiting solTNF using XPro1595 improved the pathophysiological and neurological sequelae of cerulein-induced pancreatitis in mice, which provides support of its use in patients with pancreatitis. This is the first study of its kind to identify a possible connection between hippocampal and pancreatic pathology and warrants further investigation. 


\section{KEY WORDS}

40 Acute Pancreatitis, Cerulein, Mice, Inflammation, cytokines, TNF, TNFR1, Neuropathic pain

\section{INTRODUCTION}

43 Pancreatitis is a leading cause for gastrointestinal disease-related hospital admissions, and is primarily an

44 inflammatory condition of the pancreas that can either be acute or chronic, lasting many years. Although

45 individuals with pancreatitis can progress to have quite severe complications, the majority of patients

46 endure only mild bouts of the disease with symptoms including upper abdominal epigastric pain, nausea

47 and vomiting $(1,2)$. Acute pancreatitis can be broadly classified into interstitial edematous pancreatitis

48 with peripancreatic fat stranding and fluid accumulation, or necrotizing pancreatitis that as the name

49 suggests promotes necrosis of pancreatic parenchyma and/or peripancreatic tissue (2). These differences

50 in disease pathologies has driven the creation of a plethora of existing pre-clinical animal models, with no

51 single animal model displaying all aspects of acute or chronic pancreatitis. None-the-less these models

52 frequently promote a systemic inflammatory response by either non-invasive (administration of toxins,

53 transgenic mice or diet based) or invasive means (vessel/duct blockage or perfusion) (3).

54

55 Studies in patients and animals have identified the disease course and severity of pancreatitis is mostly 56 governed by inflammatory cells that drive local and systemic immune responses, of which a major 57 contributor is the upregulation of the inflammatory cytokine tumor necrosis factor (TNF). TNF production 58 promotes the induction of inflammatory genes, acinar cell death and recruitment of immune cells (4-8), 59 which prompted investigation of traditional TNF inhibitory therapies to prevent or reduce these pathologies 60 and associated symptoms. Early studies in rodents modulating TNF ligand and receptor activity using TNF 61 receptor fusion proteins or anti-TNF antibodies (e.g., Etanercept, Infliximab and Adalimumab) showed 62 promise with reduced pancreatic pathologies such as edema, inflammation, necrosis and vacuolization (963 12), and similar positive outcomes were seen in patients when TNF inhibitors were administered to treat 
other cooccurring conditions $(13,14)$. Unfortunately, the abundance of side-effects in these traditional TNF inhibitors (including immunological dysfunction and even the induction of pancreatitis itself (15-19)), combined with their apparent inability to reduce mortality in early studies performed on sepsis patients (20,

67 21) dampened enthusiasm for their further use in patients with pancreatitis. More than 2 decades on 68 however, additional meta-analysis' of patients with sepsis have revealed an overall improvement in survival 69 rates $(22,23)$, when studies are sufficiently powered, and this may have encouraged the examination of 70 these traditional TNF inhibitors in patients with pancreatitis $(24,25)$. None-the-less, these traditional 71 inhibitors still promote severe side-effects, and their use should be cautioned in patients.

73 The discrepancy between these paradoxical outcomes in rodents and humans warrants further investigation, 74 but is likely due to the differences in TNF receptor subtype functions, that have complicated the TNF field 75 until recently. TNF is first produced as a transmembrane protein (tmTNF) that preferentially activates TNF receptor 2 (TNFR2: CD120b or p75/p80) (26), but once TNF is cleaved from the cell membrane to exist

77 in a soluble form (solTNF) it preferentially activates TNF receptor 1 (TNFR1: CD120a or p55/p60) (26).

78 Although the two receptors can trigger some common signaling pathways (27), TNFR2 activation generally

79 promotes beneficial outcomes such as cell survival, induction of neurogenesis, and promotion of CNS 80 autoimmunity (28-30), while TNFR1 activity generally promotes detrimental outcomes such as cell death, 81 aberrant neuronal plasticity, and exacerbation of the existing inflammatory response $(28,31,32)$. 82 Therefore, being able to selectively block the activity of solTNF/TNFR1, while sparing the activity of 83 tmTNF/TNFR2 activity, would likely prove beneficial to patients, although traditional TNF inhibitors are 84 unable to distinguish between the different TNF ligand or receptor subtypes. For this reason, a novel 85 'second generation' TNF inhibitor was developed that selectively inhibits only the soluble form of TNF 86 (solTNF: XPro1595), with no known side-effects, and has been proven to be safe and well tolerated in 87 patients (33), with an ability to reduce neuroinflammation in the brains of Alzheimer Disease patients (34). 88 Indeed, within the pancreas TNFR1 activity is known to exacerbate cell death, inflammation and edema 
89 (10), while TNFR2 promotes pancreatic regeneration $(35,36)$. Therefore, assessing the outcomes 90 selectively inhibiting solTNF using XPro1595 in rodents with pancreatitis is highly clinically relevant.

92 Replicating the symptoms of acute pancreatitis in rodents, especially induction of visceral pain is 93 challenging, as pain is a subjective experience and therefore difficult to assess in animals. None-the-less, 94 animal models are useful to identify the possible underlying mechanisms of pain necessary to create 95 therapeutic interventions. Many pre-clinical acute and chronic models of pancreatitis promote increased 96 sensitivity of the pancreas to electrical stimulation, as well as promoting the induction of neuropathic pain 97 (detection of a stimulus not normally detectable) in regions both local (abdomen) and distant (hindpaw) to 98 the site of inflammatory origin (37-44), suggesting activation of both normal pain pathways and central sensitization. Alterations to peripheral $\mathrm{A} \delta$ and $\mathrm{C}$ fiber activity promote the induction of pain $(45,46)$, while peripheral targets such as ion channels regulating neural sensitization $(47,48)$, and release of chemical mediators of inflammation such as pro-inflammatory cytokines (e.g. TNF/TNFR1) modulating these effects (47, 49-51). Central plasticity also overlays these pain pathways, involving central brain structures such as the hippocampus whereby reductions in synaptic protein expression can reduce LTP (52-54), leading to

104 loss of input to cortical pain sensing regions (e.g somatosensory and prefrontal cortices) $(55,56)$. 105 Importantly, established rodent models of neuropathic pain identify hippocampal TNF/TNFR1 activity 106 regulates the peripheral hypersensitivity $(52,57,58)$. Therefore, the systemic inflammatory response in 107 individuals with pancreatitis that upregulates TNF/TNFR1 activity may play a substantial role in both the 108 induction of pancreatic pathology and neuropathic pain.

110 For these reasons, we sought to investigate the effects of using the novel non-opioid 'second-generation' 111 biologic XPro1595 to selectively bind and neutralize solTNF in a mouse model of pancreatitis. XPro1595 112 has a 17-hour half-life, can cross the blood-brain-barrier, has been successfully used in numerous pre113 clinical inflammatory disease models (59-63), and is safe and well-tolerated in both cancer and Alzheimer 
114 Disease patients $(33,34,64,65)$. The use of XPro1595 therefore has a high potential for translation to the 115 clinic with the promise to improve outcomes in inflammatory pancreatic conditions.

117 METHODS

$118 \underline{\text { Animals }}$

119 Male C57Bl/6J mice aged 2 to 4 months were used for the current study. Animals were housed in a 12-

120 hour light/dark cycle with food and water ad libitum. Procedures related to animal use were approved by

121 the Virginia Commonwealth University Institutional Animal Care and Use Committee (in accordance with

122 NIH care and use of laboratory animals).

123

124 Acute Pancreatitis Model

125 On a single day, mice received 8 intraperitoneal injections of cerulein $(50 \mu \mathrm{g} / \mathrm{kg}$; Sigma) or vehicle $(0.9 \%$ 126 saline), over 7 hours, spaced an hour apart each. Injections were alternated between the left and right sides 127 of the abdomen to minimize any possible irritation from multiple needle injuries. The next morning 128 (approximately 18 hours after the last cerulein injection) mice received a subcutaneous injection of either 129 XPro1595 (10 mg/kg, INmuneBio) or vehicle (0.1M PBS).

$131 \quad$ Blood Collection and Amylase Analysis

132 Mice were anaesthetized with ketamine $(75 \mathrm{mg} / \mathrm{kg})$ and xylazine $(14 \mathrm{mg} / \mathrm{kg})$ by intraperitoneal injection, 133 cardiac blood was collected into $1.5 \mathrm{ml}$ polypropylene tubes and incubated on ice for 15 minutes, prior to 134 centrifugation at $2000 \mathrm{rpm}$ for 10 minutes. The resultant supernatant was removed and stored at $-80{ }^{\circ} \mathrm{C}$. 135 On the day of analysis, serum was defrosted on ice, and approximately $40 \mu 1$ loaded into a VETSCAN 136 'Comprehensive Diagnostic' rotor (Abaxis Inc.), prior to being analyzed in a Vetscan VS2 (Abaxis Inc.).

138 Histological Preparation, Staining and Immunohistochemistry 
Mice were anaesthetized with ketamine $(75 \mathrm{mg} / \mathrm{kg})$ and xylazine $(14 \mathrm{mg} / \mathrm{kg})$ by intraperitoneal injection,

140 prior to undergoing transcardial perfusion using approximately $15 \mathrm{ml} \mathrm{PBS}$, followed by approximately $4 \%$

141 paraformaldehyde (Sigma). Tissue was dissected, stored in $4 \%$ paraformaldehyde for 2 hours,

142 cryoprotected in $20 \%$ sucrose in PBS for 48 hours, and then quickly frozen in OCT over isopentane on dry

143 ice, and stored at $-80{ }^{\circ} \mathrm{C}$. Serial frozen coronal sections were cut $40 \mu \mathrm{m}$ thick through the pancreas and

144 hippocampus. Some slides underwent hematoxylin and eosin (H\&E) staining to assess pancreas

145 inflammatory infiltrates and tissue integrity. Other slides underwent immunohistochemical analysis to

146 further assess inflammatory state. Slides containing sections of either pancreas or brain were permeabilized

147 with $0.2 \%$ triton X-100 (Sigma) in $2 \%$ fish gel in PBS solution and immunohistochemically labelled with

148 the primary antibody (1:2000 rabbit anti-GFAP, Dako; 1:2000 rabbit anti-IBA-1, Wako) overnight at $4{ }^{\circ} \mathrm{C}$.

149 Sections were washed 3 times in PBS, incubated in fluorescent secondary antibodies (1:500, Molecular

150 Probes) for $30 \mathrm{~min}$ at room temperature, washed an additional 3 times in PBS, and coverslipped in Prolong

151 Gold Antifade mounting medium containing DAPI (ThermoFisher). Sections were photographed (pancreas

152 at 10x and 40x; brain at 40x) with equal exposure on an Olympus CK-2 inverted microscope, connected to

153 a 3MP Amscope digital camera (MU300-CK) with Amscope Software version 3.2, prior to analysis using

154 NIH ImageJ version 1.52a.

$156 \quad$ Histological Analysis

157 To assess pancreatic immune cell infiltration 2 and 7 days post-induction of acute pancreatitis, photographs 158 of H\&E stained pancreatic sections were semi-quantitated on an arbitrary scale within each field of view:

$1590=$ no inflammatory cells present; $1=$ some inflammatory cells present; $2=$ many inflammatory cells

160 presesnt. At 7 days, within each $H \& E$ photograph we also semi-quantitated pancreatic tissue integrity

161 (spaces between acinar cell clusters: $0=$ normal pathology; $1=$ some spaces evident; $2=$ large amount of

162 space evident appearing similar to a 'cracking' effect $)$, acinar cell atrophy $(0=$ normal pathology; $1=$ acinar

163 atrophy present but not immediately apparent; 2 = acinar atrophy prevalent throughout the tissue), and

164 integrity of intralobular duct (degree of invasion of spaces normally occupied by vessels within the large 
pancreatic lobules: $0=$ normal pathology, $1=$ some invasion present but not immediately apparent, $2=$

166 large amount of invasion present). Values for each photograph were averaged per section, per animal, and

167 then per group. To assess the extent of circulating macrophage infiltration within the pancreas, the

168 immunohistochemistry images were quantitated for the level of IBA-1. Images were imported into ImageJ,

169 converted to gray scale and thresholded, and the area fraction of pixels positive for IBA-1 was quantitated.

170 For each photograph, IBA-1 expression level (arbitrary units) were measured in fractional areas to give an

171 average IBA-1 intensity. Values for each photograph were averaged per section, per animal, and then per

172 group. The same protocol was applied to brain sections containing hippocampus at 7 days post-induction

173 to quantitate astrocyte reactivity using the GFAP antibody.

175 Mechanical von Frey Hindpaw Neuropathic Pain

176 In a dimly lit room, a 10" x 19" extension window screen (Thermwell) was fully extended and placed atop

1772 polystyrene boxes, with a desk lamp placed behind and just under the height of the screen, angled towards

178 the investigator. Four mice at a time were placed on top of the screen, with a $600 \mathrm{ml}$ glass beaker (Pyrex)

179 placed over the top of each mouse to prevent escape. A disposable underpad was draped over the beakers

180 to minimize any light and/or movement stimulation. After 15 minutes acclimatization under the beaker,

181 hindpaw hypersensitivity was assessed by holding the von Frey filament (Bioseb) handle under the screen,

182 and slowly raising the end of the filament up through the screen to press against the under-side of the

183 mouse's hindpaw walking pad until a slight bend was observed in the fiber. Continued

184 advancement/bending of the filament does not necessarily produce more force of application. The

185 investigator tested the lightest filament first, and sequentially tested up through the filament sizes until a

186 positive result was established. A positive result was the mouse noticing 3 out of 5 consecutive tests for

187 each filament, defined as the mouse withdrawing its foot, licking or shaking its foot, or rapidly moving its

188 body away from the stimulus. Once a positive result was established for each mouse, the testing was

189 concluded for that mouse for that day. The testing occurred as rapidly as possible to reduce restraint 
distress, although it was noticed that mice would often fall asleep during testing, which required gentle

191 tapping from underneath the screen to wake up the animal.

\section{$193 \quad \underline{\text { Statistical Analysis }}$}

194 All data were assessed for homogeneity of variance, after which statistical analysis was performed.

195 Histological differences were assessed using the Student's t-test, and behavioral differences (intra- and 196 inter-group analysis) were assessed using two-way repeated measures analysis of variance with Student-

197 Newman-Keuls method post hoc in SigmaPlot 13.0 where significance was $<0.05$. Data in figures are 198 expressed as mean \pm standard error of the mean.

\section{RESULTS}

201 Cerulein administration induces a temporary increase in serum amylase levels in mice

202 Increased expression of serum amylase activity in patients supports the diagnosis of acute pancreatitis.

203 Therefore, we wanted to confirm whether 8 intraperitoneal injections of cerulein each hour over the course 204 of 7 hours increases serum amylase levels. Mice received 8 injections of either cerulein $(50 \mathrm{mg} / \mathrm{kg})$ or 205 vehicle, and a terminal blood draw was performed 6 hours after the last cerulein injection. Biochemical 206 analysis of the animal's serum using a VetscanVS2 Comprehensive Diagnostic Rotor identified cerulein 207 administration led to over a 6-fold increase in serum amylase levels, compared to vehicle-treated mice 208 (Figure 1). Next, to identify the time course of serum amylase expression, serum amylase levels were also 209 assessed 18 hours after the last cerulein injection on the prior day. At this later timepoint, biochemical 210 analysis reveals amylase levels were no longer significantly different to vehicle-treated (i.e. non211 pancreatitis) animals, suggesting the cerulein treatment protocol promotes a strong but transient increase in 212 serum amylase levels.

214 Selective inhibition of solTNF prevents immune cell infiltration into the pancreas following cerulein215 induction of acute pancreatitis 
To identify the possible role of solTNF/TNFR1 activity in the disease course of pancreatitis we used

217 cerulein to induce acute pancreatitis in mice, treated the next day with either XPro1595 or vehicle S.C., and

218 allowed the mice to survive a further 24 hours ( 48 hours after cerulein administration). The mice were

219 transcardially perfused and the pancreas removed and processed for H\&E staining. The number of

220 inflammatory cells present was semi-quantitated on an arbitrary scale. Observations by an investigator

221 blinded to the treatment regime, identified that the vehicle-treated acute pancreatitis mice had a significant

222 influx of inflammatory cells 48 hours after induction, as observed by H\&E (score $=1.8 \pm 0.03$ ) (Figure

$2232 \mathrm{~A}, \mathrm{~B} \& \mathrm{G})$. In comparison, the XPro1595-treated acute pancreatitis mice had a significant reduction in the

224 number of inflammatory cells present 48 hours after induction (score $=0.5 \pm 0.4$ ) (Figure $2 \mathrm{D}, \mathrm{E} \& \mathrm{G})$. By 7

225 days post-induction, inflammatory infiltrates were absent in both XPro1595- and vehicle-treated acute

226 pancreatitis groups (score $=0)($ Figure $2 \mathrm{C}, \mathrm{F} \& \mathrm{G})$, suggesting the inflammatory response within the pancreas

227 resolves itself within a week, in accordance with other published rodent studies (66-68). To confirm the

228 resolution of an inflammatory response in the same 7-day tissue, we semi-quantitated the level of ionizing

229 binding adaptor protein 1 (IBA-1), as a marker of circulating macrophages within pancreatic islets (Figure

230 2H-M). ImageJ quantitation of high-resolution pancreatic images revealed no differences in IBA-1

231 expression at 7 days between vehicle- or XPro1595 treated mice (Figure 2N).

232

233 Selective inhibition of solTNF prevents adverse pancreatic pathology 7 days following cerulein-induction

234 of acute pancreatitis

235 We next wanted to identify whether an early alteration in pancreatic inflammatory infiltrates had other 236 effects on pancreas pathology at a later timepoint. For this, 7 days after the induction of acute pancreatitis 237 we semi-quantitated pancreatic tissue integrity ('cracking' effect within small acinar clusters). We 238 identified that administering cerulein reduces tissue integrity within small cell clusters (Figure $3 \mathrm{~A} \& \mathrm{C}$ ), 239 while XPro1595 treatment prevented this effect (significantly less than vehicle-treated pancreatitis mice, 240 and not different to non-pancreatitis mice) (Figure 3B\&C). We also semi-quantitated acinar cell atrophy. 241 We observed that vehicle-treated cerulein-induced acute pancreatitis promotes acinar atrophy by day 7 
242 (Figure 3D\&F), compared to vehicle-treated non-pancreatitis mice (Figure 3F). In contrast, the XPro1595-

243 treated pancreatitis group did not display acinar atrophy (significantly less than vehicle-treated pancreatitis

244 mice, and not different to non-pancreatitis mice) (Figure 3E\&F). We further assessed the integrity of the

245 intralobular duct between large pancreatic lobules. Cerulein-induced pancreatitis promoted significant

246 disruption of pathology between the large pancreatic lobules, whereby acinar clusters within lobules often

247 invaded these spaces (Figure 3G\&I). This effect was not observed in the XPro1595-treated pancreatitis

248 group (not significantly different to non-pancreatitis mouse group) (Figure 3H\&I).

250 Selective inhibition of solTNF using XPro1595 attenuates cerulein-induced neuropathic pain

251 Acute pancreatitis often promotes severe and constant pain in the upper abdomen, which can extend around

252 to the back, and last for a few days. In accordance with this, many pre-clinical rodent models display both

253 pancreatic and referred neuropathic pain in both the abdomen and hindpaws (37-44). To assess the role of

254 solTNF in the induction of pancreatitis-induced neuropathic pain, we measured the level of hindpaw

255 mechanical hypersensitivity at 3, 5 and 7 days post-induction, in mice treated with and without XPro1595.

256 Vehicle-treated non-pancreatitis mice (i.e. vehicle S.C. and I.P.) were assessed to establish baseline

257 sensitivity response, set at $100 \%$. We observed the hindpaw sensitivity of XPro1595-treated non-

258 pancreatitis mice (i.e. XPro1595 S.C., and vehicle I.P.) was not different from vehicle-treated non-

259 pancreatitis mice over the testing period (Figure 4), suggesting XPro1595 does not regulate hindpaw

260 hypersensitivity under non-pathogenic conditions. Next, we assessed the hindpaw sensitivity of mice with

261 ceruline-induced acute pancreatitis. We identified that vehicle-treated acute pancreatitis mice (i.e. Vehicle

262 S.C., and cerulein I.P.) displayed persistent hindpaw hypersensitivity, beginning from the first day of testing

263 (day 3) until the last (day 7). In contrast, the hindpaw hypersensitivity of XPro1595-treated pancreatitis

264 mice (XPro1595 S.C., and cerulein I.P.), was not significantly different to baseline control mice at any time

265 point tested, and was significantly better than vehicle-treated pancreatitis mice on days 5 and 7. 

pancreatitis in mice

In recent years there has been strong support for the involvement of the hippocampal inflammatory response

270 in the development of peripheral pain. Specifically, rodent models show hippocampal TNF/TNFR1 activity

271 regulates hindpaw neuropathic pain $(52,58)$. Since acute pancreatitis promotes a systemic inflammatory

272 response in both humans and rodents $(69,70)$, including TNF upregulation within the hippocampus (71),

273 we sought to determine whether our model of pancreatitis promotes an inflammatory state within the

274 hippocampus that could play a role in the development of peripheral hindpaw mechanical hypersensitivity.

275 We semi-quantitated hippocampal GFAP expression, as a marker of astroglial reactivity 7 days after

276 cerulean administration. We observed that cerulein-induced acute pancreatitis increased the tendency to

277 for astrocyte reactivity (GFAP expression) in the hippocampal CA1 region 7 days post-induction, compared

278 to non-pancreatitis mice (Figure 5A,B\&E), which was not apparent in the XPro1595-treated pancreatitis 279 group (Figure 5C,D\&E).

\section{DISCUSSION}

282 The onset of acute pancreatitis causes abdominal tenderness and pain, as well as nausea and vomiting that 283 coincides with a spike in the blood pancreatic enzymes amylase and lipase (72), and an inflammatory 284 response (69). Many causes of acute pancreatitis have been identified including pancreatic duct obstruction, 285 alcoholism and a genetic mutation, with management including removal of any obstruction/s, nutritional 286 regulation (including pancreatic enzyme supplementation and hydration), and pain management (73).

287 Pharmacologic interventions have targeted the inhibition of proteolytic enzymes using broad spectrum anti288 protease inhibitors that showed variable outcomes in animals if delivered before disease onset $(74,75)$. 289 Unfortunately, these inhibitors failed to show any effect in patients, possibly due to administration at a time 290 point after peak enzymatic activity, which may be unavoidable given the short peak in enzyme activity in 291 patients $(76,77)$. Another pharmacological direction is to regulate the immune response, which also 292 displays different phases of pro- and anti-inflammation, but which may represent a more clinically relevant 
timepoint. Animal studies inhibiting pro-inflammatory mediators including IL-6, and ICAM, or bolstering anti-inflammatory mediators such as IL-10 have also shown variable successes (78-82), but enthusiasm for their use in patients has diminished due to limited benefits observed in regulating the inflammatory response (83-86). Notably however, early studies in rodents using TNF inhibitors showed promise with improved 297 pancreatic pathology (9-12), with positive outcomes also seen in patients $(13,14)$, although their abundance 298 of side-effects combined with their inability to reduce mortality in early studies on sepsis patients $(20,21)$ 299 dampened enthusiasm for their further use in patients with pancreatitis. More than 2 decades later however, additional meta-analysis' reveal an overall improvement in survival rates in patients with sepsis when studies are sufficiently powered $(22,23)$. That combined with the development of a novel selective inhibitor of solTNF (XPro1595) with no known side-effects, that has proven to be safe and well tolerated (33), with an ability to reduce neuroinflammation in patients (34), warrants additional investigation. Indeed, our preclinical studies identify that selectively inhibiting solTNF by administrating XPro1595 in a clinically relevant window reduces the course of the disease by limiting pancreatic inflammatory infiltrates. This early reduction in inflammatory severity prevents subsequent pancreatic pathological damage, despite this study being performed in a rodent model of pancreatitis (cerulein induction) that is known to resolve the inflammatory response within 7 days.

One of our important findings in these studies is the improvement of neuropathic pain "referred pain" over the course of the study in the XPro1595-treated mice, even after the resolution of the inflammatory response 312 in all groups (Day 7). This is important because it suggests that the early inflammatory response is a 313 significant contributor to the development of pancreatitis-induced pain, which can be alleviated by 314 selectively inhibiting solTNF. Several lines of evidence suggest TNF plays a key role in regulating pain. 315 First, TNF can regulate signaling along the traditional pain pathways at the level of the nociceptors (87, 316 88), dorsal root ganglion $(50,89)$, thalamus (90), and somatosensory cortex (90). In support of this, 317 administering infliximab to block TNF in patients with rheumatoid arthritis reduced pain-induced CNS 318 activity (90). Second, strong evidence supports of role of TNF throughout the limbic system to regulate 
319 pain $(52-54,90,91)$, possibly by incorporating emotional memories of pain. One region of the limbic 320 system that has gained a lot of attention is the hippocampus whereby hippocampal TNF/TNFR1 activity 321 regulates the severity of neuropathic pain $(52-54,91)$. Indeed, in our mouse model we observed a strong 322 tendency for upregulation of GFAP in the hippocampus 7 days after the induction of acute pancreatitis 323 suggesting that in our model hippocampal TNF/TNFR1 activity could be contributing to the induction of 324 neuropathic pain since reactive astrocytes are known synthesizes of excess TNF $(92,93)$. However, the 325 subcutaneous administration of XPro1595, while clinically relevant, prevents determination of the 326 molecular mechanisms involved.

327

328 


\section{CONCLUSION}

330 Excess levels of the inflammatory cytokine TNF plays a prominent role in many inflammatory disease

331 pathologies, including the induction of pancreatitis. Attempts to use TNF receptor fusion proteins or

332 monoclonal antibodies to regulate this cytokines function have shown some successes clinically, but these

333 have been fraught with complications due to their numerous adverse side-effects, including drug-induced

334 acute pancreatitis. Our data provide support for the clinical use of a novel second generation TNF inhibitor

335 XPro1595 that selectively inhibits only the detrimental soluble form of TNF to prevent the disease sequelae,

336 while sparing the beneficial transmembrane form of TNF to allow reparative cellular mechanisms to remain.

338 ABBREVIATIONS

339 LTP long term potentiation

340 solTNF soluble form of tumor necrosis factor

341 tmTNF transmembrane form of tumor necrosis factor

342 TNFR1 tumor necrosis factor receptor 1

343 TNFR2 tumor necrosis factor receptor 2

344 DECLARATIONS

345 Ethics approval and consent to participate

346 All experiments were performed under approval of the VCU Institutional Animal Care and Use

347 Committee.

348 Consent for publication

349 Not applicable.

350 Availability of data and materials

351 The datasets generated and/or analyzed during the current study are available from the corresponding

352 author on reasonable request.

\section{Competing interests}

354 The authors declare that they have no competing interests. 


\section{Funding}

We gratefully acknowledge the grant support from the Virginia Commonwealth Neurotrauma Initiative funding to KJD (FP00001476), and Virginia Commonwealth University Department of Surgery pilot funding to KJD. Funding bodies did not contribute to the design of study or collection, analysis, interpretation of data or writing of the manuscript.

\section{Author's contributions}

RR and MD performed the experiments and tabulated the data. KJD designed, planned, funded, analyzed and interpreted the data. All authors read and approved the final manuscript.

\section{Acknowledgements}

We thank Dr. Jad Khoraki (VCU, Surgery) for advice on pancreatic pathological outcomes, Dr. Haoxuan (Anna) $\mathrm{Xu}$ (VCU, Surgery) for assistance with manuscript writing, and Dr. Michael Idowu (VCU, Pathology) for advice on pancreatic pathological outcomes. We thank INmuneBio Inc. for providing the

\section{REFERENCES}

371 1. Bugiantella W, Rondelli F, Boni M, Stella P, Polistena A, Sanguinetti A, et al. Necrotizing 372 pancreatitis: A review of the interventions. Int J Surg. 2016;28 Suppl 1:S163-71.

373 2. Thoeni RF. Imaging of Acute Pancreatitis. Radiol Clin North Am. 2015;53(6):1189-208.

374 3. Zhao JB, Liao DH, Nissen TD. Animal models of pancreatitis: can it be translated to human pain 375 study? World J Gastroenterol. 2013;19(42):7222-30.

376 4. Bhatia M, Wong FL, Cao Y, Lau HY, Huang J, Puneet P, et al. Pathophysiology of acute pancreatitis. 377 Pancreatology. 2005;5(2-3):132-44.

378 5. Malleo G, Mazzon E, Siriwardena AK, Cuzzocrea S. Role of tumor necrosis factor-alpha in acute 379 pancreatitis: from biological basis to clinical evidence. Shock. 2007;28(2):130-40.

380 6. Hughes CB, Gaber LW, Kotb M, Mohey el-Din AB, Pabst M, Gaber AO. Induction of acute 381 pancreatitis in germ-free rats: evidence of a primary role for tumor necrosis factor-alpha. Surgery. 382 1995;117(2):201-5.

383 7. Grewal HP, Kotb M, el Din AM, Ohman M, Salem A, Gaber L, et al. Induction of tumor necrosis 384 factor in severe acute pancreatitis and its subsequent reduction after hepatic passage. Surgery. 385 1994;115(2):213-21.

386 8. Norman JG, Fink GW, Franz MG. Acute pancreatitis induces intrapancreatic tumor necrosis factor 387 gene expression. Arch Surg. 1995;130(9):966-70. 
9. Hughes CB, Grewal HP, Gaber LW, Kotb M, El-din AB, Mann L, et al. Anti-TNFalpha therapy improves survival and ameliorates the pathophysiologic sequelae in acute pancreatitis in the rat. Am J Surg. 1996;171(2):274-80.

10. Denham W, Yang J, Fink G, Denham D, Carter G, Ward K, et al. Gene targeting demonstrates additive detrimental effects of interleukin 1 and tumor necrosis factor during pancreatitis. Gastroenterology. 1997;113(5):1741-6.

11. Oruc N, Ozutemiz AO, Yukselen V, Nart D, Celik HA, Yuce G, et al. Infliximab: a new therapeutic agent in acute pancreatitis? Pancreas. 2004;28(1):e1-8.

396 12. Tekin SO, Teksoz S, Terzioglu D, Arikan AE, Ozcevik H, Uslu E. Use of infliximab in treatment of acute pancreatitis. Bratisl Lek Listy. 2015;116(3):167-72.

398 13. Triantafillidis JK, Cheracakis P, Hereti IA, Argyros N, Karra E. Acute idiopathic pancreatitis complicating active Crohn's disease: favorable response to infliximab treatment. Am J Gastroenterol. 2000;95(11):3334-6. treatment of psoriasis in a patient with acute-on-chronic pancreatitis. Dermatology. 2013;227(3):193-6.

15. Werlang ME, Lewis MD, Bartel MJ. Tumor Necrosis Factor Alpha Inhibitor-Induced Acute Pancreatitis. ACG Case Rep J. 2017;4:e103.

16. Gunawan F, Fayyaz B, Mihardja TO. Etanercept - A culprit agent in acute pancreatitis? J Community Hosp Intern Med Perspect. 2019;9(2):147-9.

17. Sahu KKL, A.; Mishra, A.K.; Zhang, P. Adalimumab-related hypertriglyceridemia and acute pancreatitis. QJM. 2019;113(4):2.

18. Miramontes PM, C.; Calero, I.; Plata, A. Acute fulminant drug induced necrotizing pancreatitis in a patient with ankylosing spondylitis Galicia Clinica. 2015;76(1):2.

411 19. Stobaugh DJ, Deepak P. Effect of tumor necrosis factor-alpha inhibitors on drug-induced

20. Grau GE, Maennel DN. TNF inhibition and sepsis -- sounding a cautionary note. Nat Med. 1997;3(11):1193-5.

21. Fisher CJ, Jr., Agosti JM, Opal SM, Lowry SF, Balk RA, Sadoff JC, et al. Treatment of septic shock with the tumor necrosis factor receptor:Fc fusion protein. The Soluble TNF Receptor Sepsis Study Group. N Engl J Med. 1996;334(26):1697-702.

22. Qiu P, Cui X, Sun J, Welsh J, Natanson C, Eichacker PQ. Antitumor necrosis factor therapy is associated with improved survival in clinical sepsis trials: a meta-analysis. Crit Care Med. 2013;41(10):2419-29.

23. Lv S, Han M, Yi R, Kwon S, Dai C, Wang R. Anti-TNF-alpha therapy for patients with sepsis: a systematic meta-analysis. Int J Clin Pract. 2014;68(4):520-8.

24. NIH.ClinicalTrials.gov. Randomised Treatment of Acute Pancreatitis With Infliximab: Double-blind Multi-centre Trial (RAPID-I) (RAPID-I) https://clinicaltrials.gov/ct2/show/NCT036842782019 [

25. ISRCTN.Registry. Phase IIb, randomised, double-blind, placebo-controlled, multi-centre trial of infliximab with transcriptomic biomarker and mechanism evaluation in patients with acute pancreatitis http://www.isrctn.com/ISRCTN169357612020 [

26. Fischer R, Marsal J, Gutta C, Eisler SA, Peters N, Bethea JR, et al. Novel strategies to mimic transmembrane tumor necrosis factor-dependent activation of tumor necrosis factor receptor 2 . Sci Rep. 2017;7(1):6607.

27. Wajant $H$, Siegmund D. TNFR1 and TNFR2 in the Control of the Life and Death Balance of Macrophages. Front Cell Dev Biol. 2019;7:91.

28. Longhi L, Perego C, Ortolano F, Aresi S, Fumagalli S, Zanier ER, et al. Tumor necrosis factor in traumatic brain injury: effects of genetic deletion of p55 or p75 receptor. J Cereb Blood Flow Metab. 2013;33(8):1182-9. 
29. Faustman DL, Davis M. TNF Receptor 2 and Disease: Autoimmunity and Regenerative Medicine. Front Immunol. 2013;4:478.

30. Atretkhany KN, Mufazalov IA, Dunst J, Kuchmiy A, Gogoleva VS, Andruszewski D, et al. Intrinsic TNFR2 signaling in T regulatory cells provides protection in CNS autoimmunity. Proc Natl Acad Sci U S A. 2018;115(51):13051-6.

31. Yang J, You Z, Kim HH, Hwang SK, Khuman J, Guo S, et al. Genetic analysis of the role of tumor necrosis factor receptors in functional outcome after traumatic brain injury in mice. J Neurotrauma. 2010;27(6):1037-46.

32. Knoblach SM, Fan L, Faden Al. Early neuronal expression of tumor necrosis factor-alpha after experimental brain injury contributes to neurological impairment. J Neuroimmunol. 1999;95(1-2):115-25. 33. INmuneBiolnc. INmune Bio Reports Positive Preliminary Data from INB03 Phase I Clinical Trial in Cancer. $\quad$ https://wwwglobenewswirecom/news-release/2019/08/05/1896903/0/en/INmune-BioReports-Positive-Preliminary-Data-from-INB03-Phase-I-Clinical-Trial-in-Cancerhtml. 2019.

34. INmuneBiolnc. INmune Bio Announces Final Phase I Clinical Data for its Soluble TNF Inhibitor, INB03, Demonstrates Efficacy and Safety; INB03 is Advancing to Phase II Trials. https://wwwglobenewswirecom/news-release/2019/12/17/1961610/0/en/INmune-Bio-AnnouncesFinal-Phase-I-Clinical-Data-for-its-Soluble-TNF-Inhibitor-INB03-Demonstrates-Efficacy-and-Safety-INB03is-Advancing-to-Phase-II-Trialshtml. 2019.

35. Ban L, Zhang J, Wang L, Kuhtreiber W, Burger D, Faustman DL. Selective death of autoreactive T cells in human diabetes by TNF or TNF receptor 2 agonism. Proc Natl Acad Sci U S A. 2008;105(36):136449.

36. Okubo Y, Torrey H, Butterworth J, Zheng H, Faustman DL. Treg activation defect in type 1 diabetes: correction with TNFR2 agonism. Clin Transl Immunology. 2016;5(1):e56.

37. Winston JH, He ZJ, Shenoy M, Xiao SY, Pasricha PJ. Molecular and behavioral changes in nociception in a novel rat model of chronic pancreatitis for the study of pain. Pain. 2005;117(1-2):214-22. 38. Vera-Portocarrero LP, Lu Y, Westlund KN. Nociception in persistent pancreatitis in rats: effects of morphine and neuropeptide alterations. Anesthesiology. 2003;98(2):474-84.

39. Stumpf F, Algul H, Thoeringer CK, Schmid RM, Wolf E, Schneider MR, et al. Metamizol Relieves Pain Without Interfering With Cerulein-Induced Acute Pancreatitis in Mice. Pancreas. 2016;45(4):572-8.

40. Demir IE, Heinrich T, Carty DG, Saricaoglu OC, Klauss S, Teller S, et al. Targeting nNOS ameliorates the severe neuropathic pain due to chronic pancreatitis. EBioMedicine. 2019;46:431-43.

41. Irie $\mathrm{Y}$, Tsubota M, Ishikura H, Sekiguchi F, Terada Y, Tsujiuchi T, et al. Macrophage-derived HMGB1 as a Pain Mediator in the Early Stage of Acute Pancreatitis in Mice: Targeting RAGE and CXCL12/CXCR4 Axis. J Neuroimmune Pharmacol. 2017;12(4):693-707.

42. Liu L, Zhu Y, Noe M, Li Q, Pasricha PJ. Neuronal Transforming Growth Factor beta Signaling via SMAD3 Contributes to Pain in Animal Models of Chronic Pancreatitis. Gastroenterology. 2018;154(8):2252-65 e2.

43. Cattaruzza F, Johnson C, Leggit A, Grady E, Schenk AK, Cevikbas F, et al. Transient receptor potential ankyrin 1 mediates chronic pancreatitis pain in mice. Am J Physiol Gastrointest Liver Physiol. 2013;304(11):G1002-12.

44. Zhang L, Kline RHt, McNearney TA, Johnson MP, Westlund KN. Cannabinoid receptor 2 agonist attenuates pain related behavior in rats with chronic alcohol/high fat diet induced pancreatitis. Mol Pain. 2014;10:66.

45. Magerl W, Ali Z, Ellrich J, Meyer RA, Treede RD. C- and A delta-fiber components of heat-evoked cerebral potentials in healthy human subjects. Pain. 1999;82(2):127-37.

46. Traub RJ, Mendell LM. The spinal projection of individual identified A-delta- and C-fibers. J Neurophysiol. 1988;59(1):41-55.

47. Bell A. The neurobiology of acute pain. Vet J. 2018;237:55-62. 
48. De Logu F, Geppetti P. Ion Channel Pharmacology for Pain Modulation. Handb Exp Pharmacol. 2019;260:161-86.

49. Jin X, Gereau RWt. Acute p38-mediated modulation of tetrodotoxin-resistant sodium channels in mouse sensory neurons by tumor necrosis factor-alpha. J Neurosci. 2006;26(1):246-55.

50. de Macedo FHP, Aires RD, Fonseca EG, Ferreira RCM, Machado DPD, Chen L, et al. TNF-alpha mediated upregulation of NaV1.7 currents in rat dorsal root ganglion neurons is independent of CRMP2 SUMOylation. Mol Brain. 2019;12(1):117.

51. Le Bars D, Adam F. [Nociceptors and mediators in acute inflammatory pain]. Ann Fr Anesth Reanim. 2002;21(4):315-35.

52. Dellarole A, Morton P, Brambilla R, Walters W, Summers S, Bernardes D, et al. Neuropathic paininduced depressive-like behavior and hippocampal neurogenesis and plasticity are dependent on TNFR1 signaling. Brain Behav Immun. 2014;41:65-81.

53. Ren WJ, Liu Y, Zhou L, Li W, Zhong Y, Pang RP, et al. Peripheral nerve injury leads to working memory deficits and dysfunction of the hippocampus by upregulation of TNF-alpha in rodents. Neuropsychopharmacology. 2011;36(5):979-92.

54. Liu Y, Zhou L, Wang J, Li D, Ren WJ, Peng J, et al. TNF-alpha Differentially Regulates Synaptic Plasticity in the Hippocampus and Spinal Cord by Microglia-Dependent Mechanisms after Peripheral Nerve Injury. J Neurosci. 2017;37(4):871-81.

55. Cardoso-Cruz H, Lima D, Galhardo V. Impaired spatial memory performance in a rat model of neuropathic pain is associated with reduced hippocampus-prefrontal cortex connectivity. J Neurosci. 2013;33(6):2465-80.

56. Mutso AA, Petre B, Huang L, Baliki MN, Torbey S, Herrmann KM, et al. Reorganization of hippocampal functional connectivity with transition to chronic back pain. J Neurophysiol. 2014;111(5):1065-76.

57. Gerard E, Spengler RN, Bonoiu AC, Mahajan SD, Davidson BA, Ding H, et al. Chronic constriction injury-induced nociception is relieved by nanomedicine-mediated decrease of rat hippocampal tumor necrosis factor. Pain. 2015;156(7):1320-33.

58. Martuscello RT, Spengler RN, Bonoiu AC, Davidson BA, Helinski J, Ding $\mathrm{H}$, et al. Increasing TNF levels solely in the rat hippocampus produces persistent pain-like symptoms. Pain. 2012;153(9):1871-82. 59. Brambilla R, Ashbaugh JJ, Magliozzi R, Dellarole A, Karmally S, Szymkowski DE, et al. Inhibition of soluble tumour necrosis factor is therapeutic in experimental autoimmune encephalomyelitis and promotes axon preservation and remyelination. Brain. 2011;134(Pt 9):2736-54.

60. Clausen BH, Degn M, Martin NA, Couch Y, Karimi L, Ormhoj M, et al. Systemically administered anti-TNF therapy ameliorates functional outcomes after focal cerebral ischemia. J Neuroinflammation. 2014;11:203.

61. MacPherson KP, Sompol P, Kannarkat GT, Chang J, Sniffen L, Wildner ME, et al. Peripheral administration of the soluble TNF inhibitor XPro1595 modifies brain immune cell profiles, decreases betaamyloid plaque load, and rescues impaired long-term potentiation in 5xFAD mice. Neurobiol Dis. 2017;102:81-95.

62. Cavanagh C, Tse YC, Nguyen HB, Krantic S, Breitner JC, Quirion R, et al. Inhibiting tumor necrosis factor-alpha before amyloidosis prevents synaptic deficits in an Alzheimer's disease model. Neurobiol Aging. 2016;47:41-9.

63. Sama DM, Mohmmad Abdul H, Furman JL, Artiushin IA, Szymkowski DE, Scheff SW, et al. Inhibition of soluble tumor necrosis factor ameliorates synaptic alterations and $\mathrm{Ca} 2+$ dysregulation in aged rats. PLoS One. 2012;7(5):e38170.

64. ANZCTR. INB03 for patients with metastatic cancer with increased inflammatory biomarkers in peripheral blood https://www.anzctr.org.au/Trial/Registration/TrialReview.aspx?id=3747192019 [ 
65. ClinicalTrials.gov N. A Biomarker-directed Study of XPro1595 in Patients With Mild to Moderate Alzheimer's https://clinicaltrials.gov/ct2/show/NCT03943264?term=inb03\&draw=2\&rank=12020 [

66. Lugea A, Nan L, French SW, Bezerra JA, Gukovskaya AS, Pandol SJ. Pancreas recovery following cerulein-induced pancreatitis is impaired in plasminogen-deficient mice. Gastroenterology. 2006;131(3):885-99.

67. Zhang $X$, Shi $Q$, Wang $C$, Wang G. Differential susceptibility of mouse strains on pancreatic injury and regeneration in cerulein-induced pancreatitis. Int J Clin Exp Pathol. 2017;10(9):9934-44.

68. Quan S, Principe DR, Dean AE, Park SH, Grippo PJ, Gius D, et al. Loss of Sirt2 increases and prolongs a caerulein-induced pancreatitis permissive phenotype and induces spontaneous oncogenic Kras mutations in mice. Sci Rep. 2018;8(1):16501.

69. Singh VK, Wu BU, Bollen TL, Repas K, Maurer R, Mortele KJ, et al. Early systemic inflammatory response syndrome is associated with severe acute pancreatitis. Clin Gastroenterol Hepatol. 2009;7(11):1247-51.

70. Ou X, Hua Y, Liao X, Gong C, Kang Y. Cognitive impairments induced by severe acute pancreatitis are attenuated by berberine treatment in rats. Mol Med Rep. 2018;18(3):3437-44.

71. Lv Y, Jing G, Zhu G, Luo H, Li B, Xie Y, et al. Effects and mechanism of the etanercept on pancreatic encephalopathy. Mol Med Rep. 2020;21(6):2615-23.

72. Majidi S, Golembioski A, Wilson SL, Thompson EC. Acute Pancreatitis: Etiology, Pathology, Diagnosis, and Treatment. South Med J. 2017;110(11):727-32.

73. Tenner S, Baillie J, DeWitt J, Vege SS, American College of G. American College of Gastroenterology guideline: management of acute pancreatitis. Am J Gastroenterol. 2013;108(9):1400-15; 16.

74. Kruse $P$, Lasson A, Hage E. Proteases and protease inhibitors in cerulein-induced acute pancreatitis in rats. J Surg Res. 1999;85(2):294-300.

75. Leonhardt U, Seidensticker F, Stockmann F, Creutzfeldt W. Effect of camostate administration for two weeks on experimental pancreatitis in mice and rats. Pancreas. 1993;8(1):98-102.

76. Chen CC, Wang SS, Lee FY. Action of antiproteases on the inflammatory response in acute pancreatitis. JOP. 2007;8(4 Suppl):488-94.

77. Seta T, Noguchi Y, Shikata S, Nakayama T. Treatment of acute pancreatitis with protease inhibitors administered through intravenous infusion: an updated systematic review and meta-analysis. BMC Gastroenterol. 2014;14:102.

78. Norman J, Franz M, Messina J, Riker A, Fabri PJ, Rosemurgy AS, et al. Interleukin-1 receptor antagonist decreases severity of experimental acute pancreatitis. Surgery. 1995;117(6):648-55.

79. Paszkowski AS, Rau B, Mayer JM, Moller P, Beger HG. Therapeutic application of caspase 1 /interleukin-1beta-converting enzyme inhibitor decreases the death rate in severe acute experimental pancreatitis. Ann Surg. 2002;235(1):68-76.

80. Chao KC, Chao KF, Chuang CC, Liu SH. Blockade of interleukin 6 accelerates acinar cell apoptosis and attenuates experimental acute pancreatitis in vivo. Br J Surg. 2006;93(3):332-8.

81. Osman MO, Kristensen JU, Jacobsen NO, Lausten SB, Deleuran B, Deleuran M, et al. A monoclonal anti-interleukin 8 antibody (WS-4) inhibits cytokine response and acute lung injury in experimental severe acute necrotising pancreatitis in rabbits. Gut. 1998;43(2):232-9.

82. Rongione AJ, Kusske AM, Kwan K, Ashley SW, Reber HA, McFadden DW. Interleukin 10 reduces the severity of acute pancreatitis in rats. Gastroenterology. 1997;112(3):960-7.

83. Akinosoglou K, Gogos C. Immune-modulating therapy in acute pancreatitis: fact or fiction. World J Gastroenterol. 2014;20(41):15200-15.

84. Opal SM, Fisher CJ, Jr., Dhainaut JF, Vincent JL, Brase R, Lowry SF, et al. Confirmatory interleukin1 receptor antagonist trial in severe sepsis: a phase III, randomized, double-blind, placebo-controlled, multicenter trial. The Interleukin-1 Receptor Antagonist Sepsis Investigator Group. Crit Care Med. 1997;25(7):1115-24. 
85. Fisher CJ, Jr., Dhainaut JF, Opal SM, Pribble JP, Balk RA, Slotman GJ, et al. Recombinant human interleukin 1 receptor antagonist in the treatment of patients with sepsis syndrome. Results from a randomized, double-blind, placebo-controlled trial. Phase III rhIL-1ra Sepsis Syndrome Study Group. JAMA. 1994;271(23):1836-43.

86. Dumont $\mathrm{M}$, Roy $\mathrm{M}$, Jodoin PM, Morency FC, Houde JC, Xie Z, et al. Free Water in White Matter Differentiates $\mathrm{MCl}$ and AD From Control Subjects. Front Aging Neurosci. 2019;11:270.

87. Zhang XC, Kainz V, Burstein R, Levy D. Tumor necrosis factor-alpha induces sensitization of meningeal nociceptors mediated via local COX and p38 MAP kinase actions. Pain. 2011;152(1):140-9.

88. Junger $\mathrm{H}$, Sorkin LS. Nociceptive and inflammatory effects of subcutaneous TNFalpha. Pain. 2000;85(1-2):145-51.

89. Zhang K, Yang S, Luo C. TNF-alpha and TNF-R1 regulate bupivacaine-induced apoptosis in spinal cord dorsal root ganglion neuron. Eur J Pharmacol. 2018;833:63-8.

90. Hess A, Axmann R, Rech J, Finzel S, Heindl C, Kreitz S, et al. Blockade of TNF-alpha rapidly inhibits pain responses in the central nervous system. Proc Natl Acad Sci U S A. 2011;108(9):3731-6.

91. Ignatowski TA, Covey WC, Knight PR, Severin CM, Nickola TJ, Spengler RN. Brain-derived TNFalpha mediates neuropathic pain. Brain Res. 1999;841(1-2):70-7.

92. Habbas S, Santello M, Becker D, Stubbe H, Zappia G, Liaudet N, et al. Neuroinflammatory TNFalpha Impairs Memory via Astrocyte Signaling. Cell. 2015;163(7):1730-41.

93. Lieberman AP, Pitha PM, Shin HS, Shin ML. Production of tumor necrosis factor and other cytokines by astrocytes stimulated with lipopolysaccharide or a neurotropic virus. Proc Natl Acad Sci U S A. 1989;86(16):6348-52.

\section{FIGURE LEGENDS}

Figure 1: Cerulein administration promotes induction of pancreatitis. Acute pancreatitis was induced by 8 intraperitoneal injections of cerulein $(50 \mathrm{mg} / \mathrm{kg})$ or vehicle to mice, spaced an hour apart each, and serum amylase concentrations were measured 6 and 18 hours after the last cerulein injection. Cerulein-treated mice displayed a temporary spike in serum amylase concentration at 6 hours, that had reduced back to baseline levels by the next morning ( $\mathrm{n}=3$ per group). $\mathrm{NC}=$ non-cerulein, $\mathrm{C}=$ cerulein, $* * \mathrm{p}<0.01, * * * \mathrm{p}<0.001$

\section{Figure 2: XPro1595 treatment attenuates cerulein-induced pancreatic inflammatory infiltrates.}

Photomicrographs illustrate hematoxylin and eosin stained sections of mouse pancreas in non-cerulein (A\&D) and cerulein (B,C,E\&F) mice, 2 days after cerulein/vehicle administration. Vehicle-treated noncerulein mice had an absence of inflammatory infiltrates $(\mathbf{A})(n=5)$, but cerulein treatment promoted an 
614 influx of inflammatory cells within 2 days $(\mathbf{B})(\mathrm{n}=3)$, which had resolved by 7 days $(\mathbf{C} \& \mathbf{G})(\mathrm{n}=4)$.

615 XPro1595 treatment significantly reduced the immune cell infiltration at 2 days $(\mathbf{E})(\mathrm{n}=3)$, that was even

616 further reduced by 7 days $(\mathbf{F})(n=4)$. A week following pancreatitis induction the circulating macrophage

617 population was also minimal in cerulein-treated mice, independent of vehicle or XPro1595 treatment $(n=4$

618 each). $\mathrm{C}=$ cerulein, $\mathrm{V}=$ vehicle, $\mathrm{XP}=\mathrm{XPro1595,} * \mathrm{p}<0.01$, scale bars $=100 \mu \mathrm{m}$.

619

620

Figure 3: Selective inhibition of solTNF in mice with acute pancreatitis prevents pancreatic tissue

621 degradation at 7 days after induction. Photomicrographs illustrate H\&E stained pancreatic sections

622 from mice with acute pancreatitis (cerulein treated) with either vehicle- $(\mathbf{A})(\mathrm{n}=4)$ or XPro1595-treatment

623 (B) $(n=4)$, where quantification shows vehicle-treated pancreatitis mice have significant deterioration of

624 tissue integrity $(\mathbf{C})$, compared to pancreatitis mice treated with XPro1595 (n=4), or non-pancreatitis mice

$625(n=3-4)$. In accordance, the vehicle-treated pancreatitis mice also display an exacerbated level of

626 pancreatic acinar cell atrophy $(\mathbf{D})$ that is not observed in the XPro1595 treated pancreatitis group $(\mathbf{E \& F})$.

627 A week after induction of pancreatitis the intralobular ducts in the vehicle-treated group appeared to be

628 invaded by groups of acini spreading apart $(\mathbf{G})$, although this was less prominent in the XPro1595-treated

629 group $(\mathbf{H} \& \mathbf{I}) . \mathrm{NC}=$ non-cerulein, $\mathrm{C}=$ cerulein, $\mathrm{V}=$ vehicle, $\mathrm{XP}=\mathrm{XPro1595},{ }^{*} \mathrm{p}<0.05, * * \mathrm{p}<0.01$,

$630 * * * \mathrm{p}<0.001$, scale bar in $\mathrm{A} \& \mathrm{~B}=500 \mu \mathrm{m}$, scalebar in $\mathrm{D} \& \mathrm{E}=25 \mu \mathrm{m}$, scalebar in $\mathrm{G} \& \mathrm{H}=500 \mu \mathrm{m}$.

631

632 Figure 4: Soluble TNF activity reduces hindpaw mechanical hyper-sensitivity following induction

633 of acute pancreatitis in mice. Graph shows mechanical hypersensitivity of the hindpaw when touched

634 by von Frey filaments, as a percentage of pre-cerulein baseline data for each mouse. No differences were

635 observed in hypersensitivity of non-pancreatitis mice between baseline and on days 3, 5 and 7,

636 independent of treatment $(n=6-8)$. In contrast, vehicle-treated pancreatitis mice displayed significantly

637 more hypersensitivity than non-pancreatitis control mice at each time point assessed during the first week

$638(\mathrm{n}=9)$. Treating mice with XPro1595 prevented this hypersensitivity at all time-points tested $(\mathrm{n}=9)$, and

639 this group displayed significantly less hypersensitivity than the vehicle-treated pancreatitis group on the 
640 last 2 days of testing. $\mathrm{NC}=$ non-cerulein, $\mathrm{C}=$ cerulein, $\mathrm{V}=$ vehicle, $\mathrm{XP}=\mathrm{XPro1595},{ }^{*} \mathrm{p}<0.05$,

$641 * * * \mathrm{p}<0.001$

642

643 Figure 5: Hippocampal GFAP expression is more pronounced in cerulein-treated mice without

644 XPro1595 administration. CA1 hippocampal GFAP expression was semi-quantitated 7 days following

645 induction of pancreatitis in mice. Non-pancreatitis mouse groups, independent of vehicle or XPro1595

646 treatment, did not display reactive astrogliosis $(\mathbf{A} \& \mathbf{C})(n=3-4)$. In contrast, the vehicle-treated

647 pancreatitis tissue $(\mathbf{B})$ had numerous reactive astrocytes and when quantitated displayed a tendency for

648 increased GFAP expression ( $\mathrm{n}=4)$, compared to the non-pancreatitis groups, but was not statistically

649 significantly different $(\mathbf{E})$. XPro1595 treated pancreatitis mice prevented the induction of reactive

650 astrocytes $(\mathbf{D})(\mathrm{n}=4) . \mathrm{NC}=$ non-cerulein, $\mathrm{C}=$ cerulein, $\mathrm{V}=$ vehicle, $\mathrm{XP}=\mathrm{XPro1595}$, scalebar $=100 \mu \mathrm{m}$. 


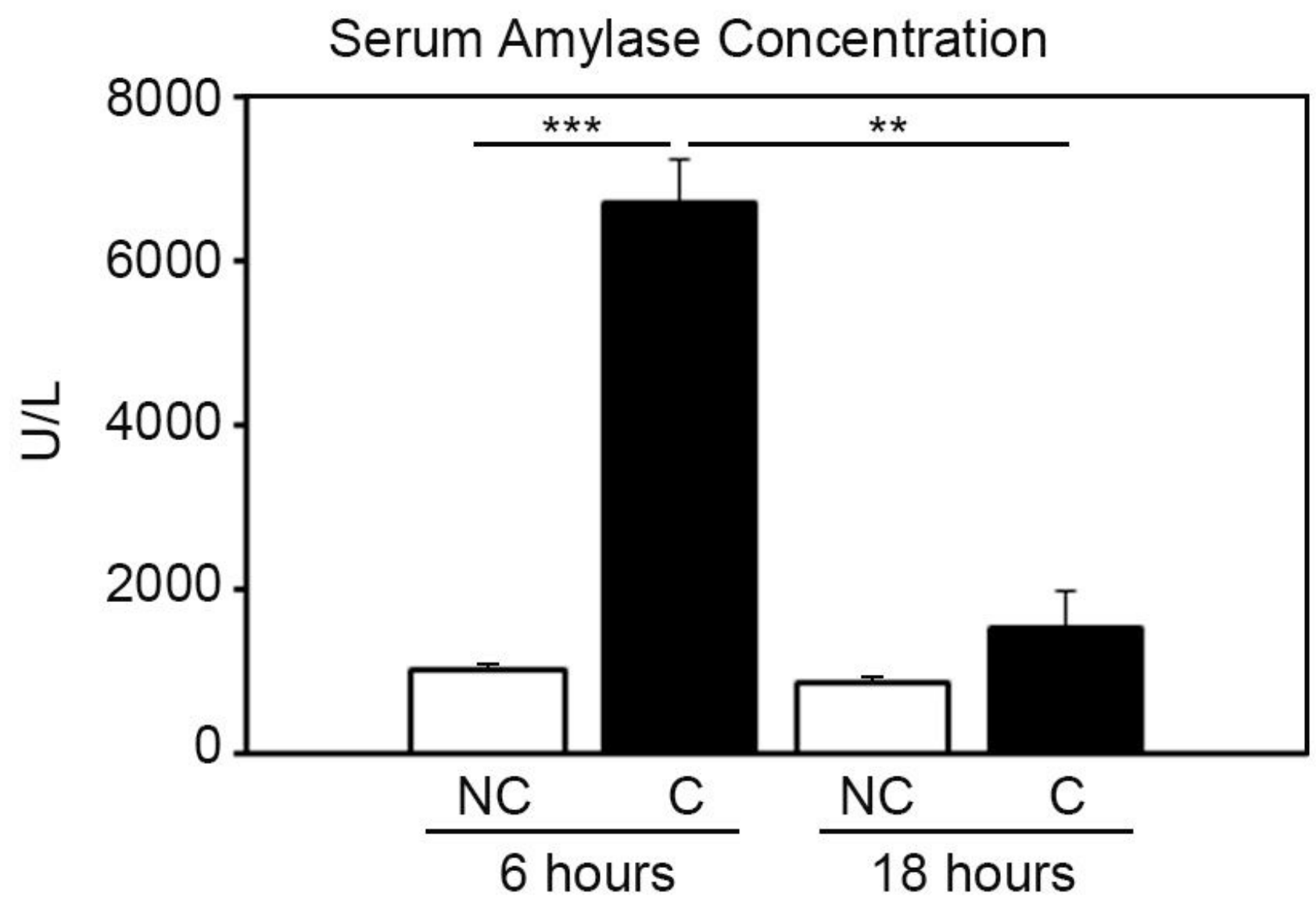

Figure 1

Cerulein administration promotes induction of pancreatitis. Acute pancreatitis was induced by 8 intraperitoneal injections of cerulein $(50 \mathrm{mg} / \mathrm{kg}$ ) or vehicle to mice, spaced an hour apart each, and serum amylase concentrations were measured 6 and 18 hours after the last cerulein injection. Cerulein-treated mice displayed a temporary spike in serum amylase concentration at 6 hours, that had reduced back to baseline levels by the next morning ( $n=3$ per group). $N C=$ non-cerulein, $C=$ cerulein, ${ }^{\star \star} p<0.01,{ }^{\star \star *} p<0.001$. 

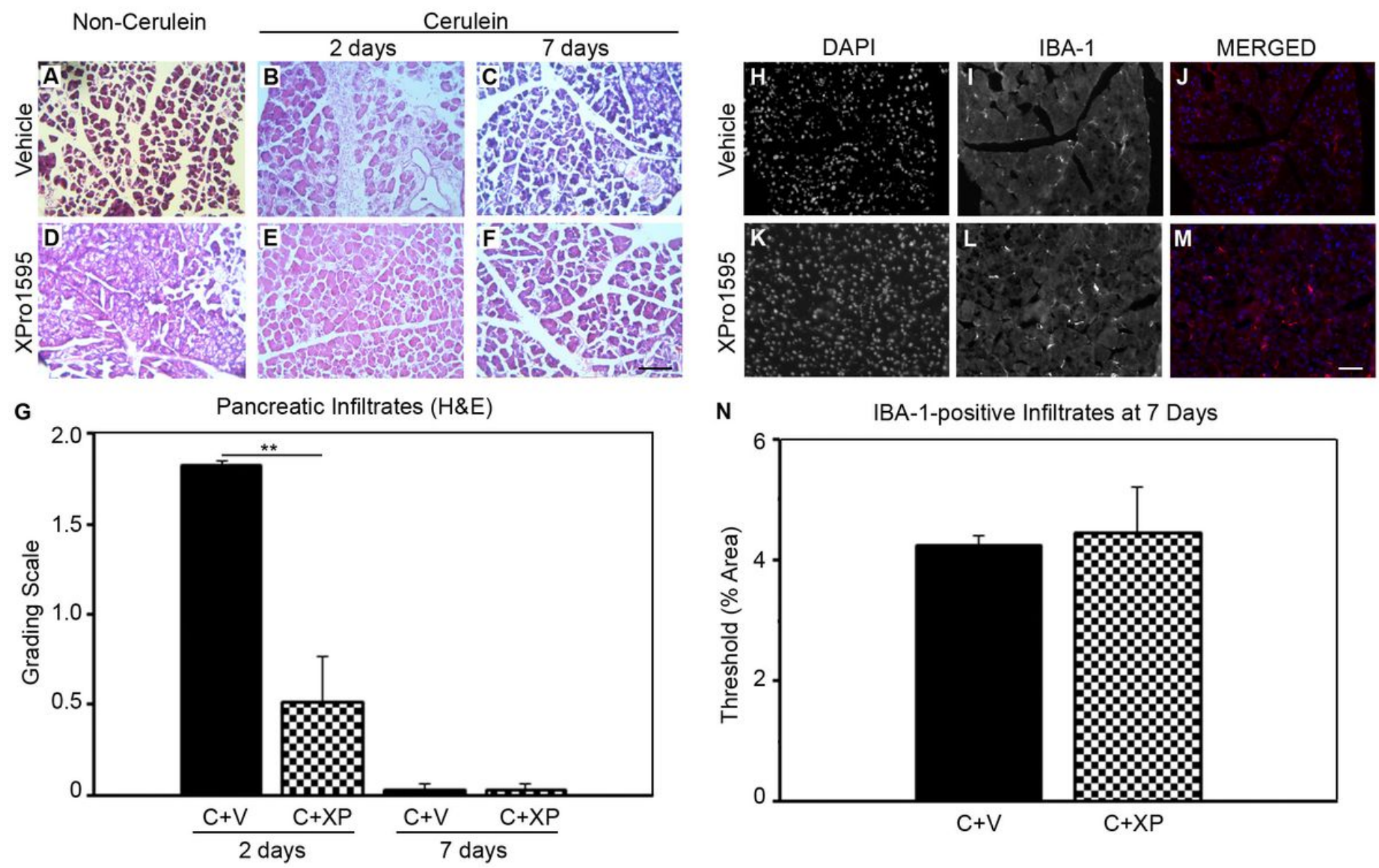

N

IBA-1-positive Infiltrates at 7 Days

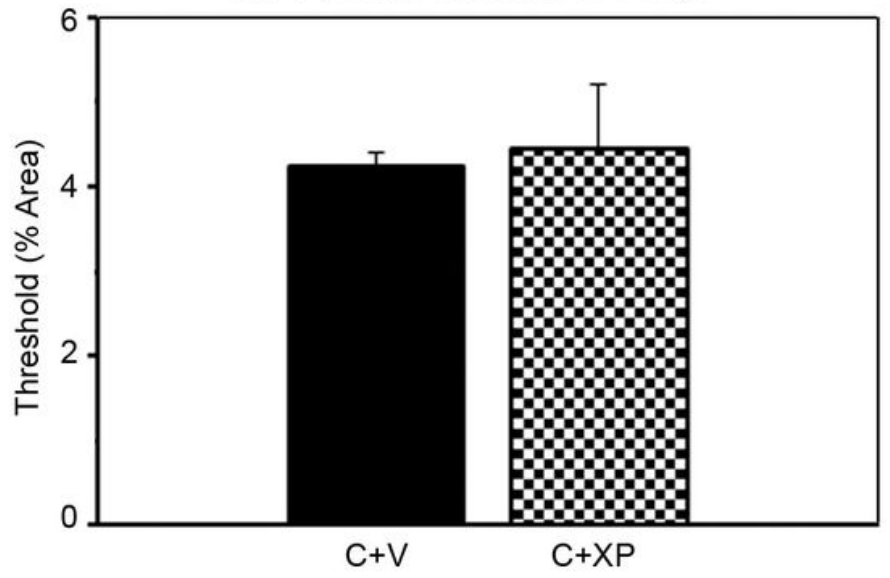

Figure 2

XPro1595 treatment attenuates cerulein-induced pancreatic inflammatory infiltrates. Photomicrographs illustrate hematoxylin and eosin stained sections of mouse pancreas in non-cerulein (A\&D) and cerulein $(B, C, E \& F)$ mice, 2 days after cerulein/vehicle administration. Vehicle-treated non-cerulein mice had an absence of inflammatory infiltrates $(A)(n=5)$, but cerulein treatment promoted an influx of inflammatory cells within 2 days $(B)(n=3)$, which had resolved by 7 days $(C \& G)(n=4)$. XPro1595 treatment significantly reduced the immune cell infiltration at 2 days $(E)(n=3)$, that was even further reduced by 7 days $(F)(n=4)$. A week following pancreatitis induction the circulating macrophage population was also minimal in cerulein-treated mice, independent of vehicle or XPro1595 treatment $(n=4$ each). $C=$ cerulein, $V=$ vehicle, $\mathrm{XP}=$ XPro1595, ${ }^{\star *} \mathrm{p}<0.01$, scale bars $=100 \mu \mathrm{m}$. 

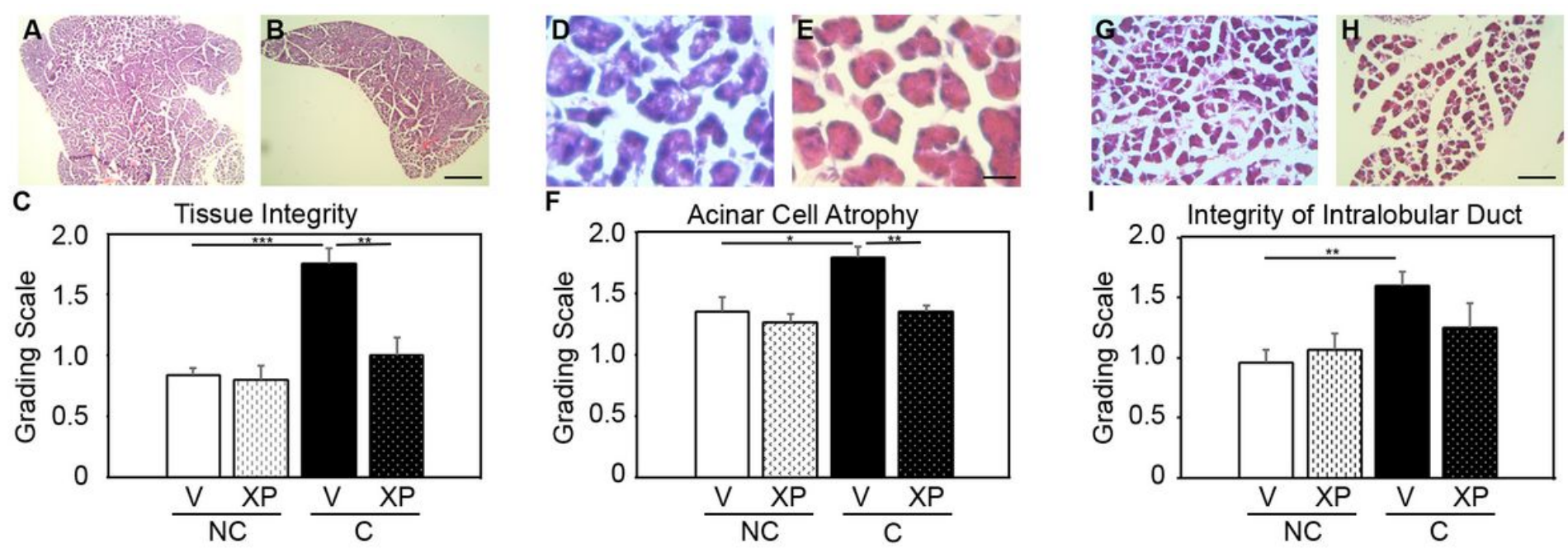

Figure 3

Selective inhibition of solTNF in mice with acute pancreatitis prevents pancreatic tissue degradation at 7 days after induction. Photomicrographs illustrate H\&E stained pancreatic sections from mice with acute pancreatitis (cerulein treated) with either vehicle- $(A)(n=4)$ or XPro1595-treatment $(B)(n=4)$, where quantification shows vehicle-treated pancreatitis mice have significant deterioration of tissue integrity (C), compared to pancreatitis mice treated with XPro1595 $(n=4)$, or non-pancreatitis mice $(n=3-4)$. In accordance, the vehicle-treated pancreatitis mice also display an exacerbated level of pancreatic acinar cell atrophy (D) that is not observed in the XPro1595 treated pancreatitis group (E\&F). A week after induction of pancreatitis the intralobular ducts in the vehicle-treated group appeared to be invaded by groups of acini spreading apart $(G)$, although this was less prominent in the XPro1595-treated group $(H \& I) . N C=$ non-cerulein, $C=$ cerulein, $V=$ vehicle, $X P=X P r 01595,{ }^{*} p<0.05,{ }^{*} p<<0.01,629{ }^{*}{ }^{*} p<0.001$, scale bar in $A \& B=500 \mu \mathrm{m}$, scalebar in $\mathrm{D} \& \mathrm{E}=25 \mu \mathrm{m}$, scalebar in $\mathrm{G} \& \mathrm{H}=500 \mu \mathrm{m}$. 


\section{Hindpaw Neuropathic Pain}

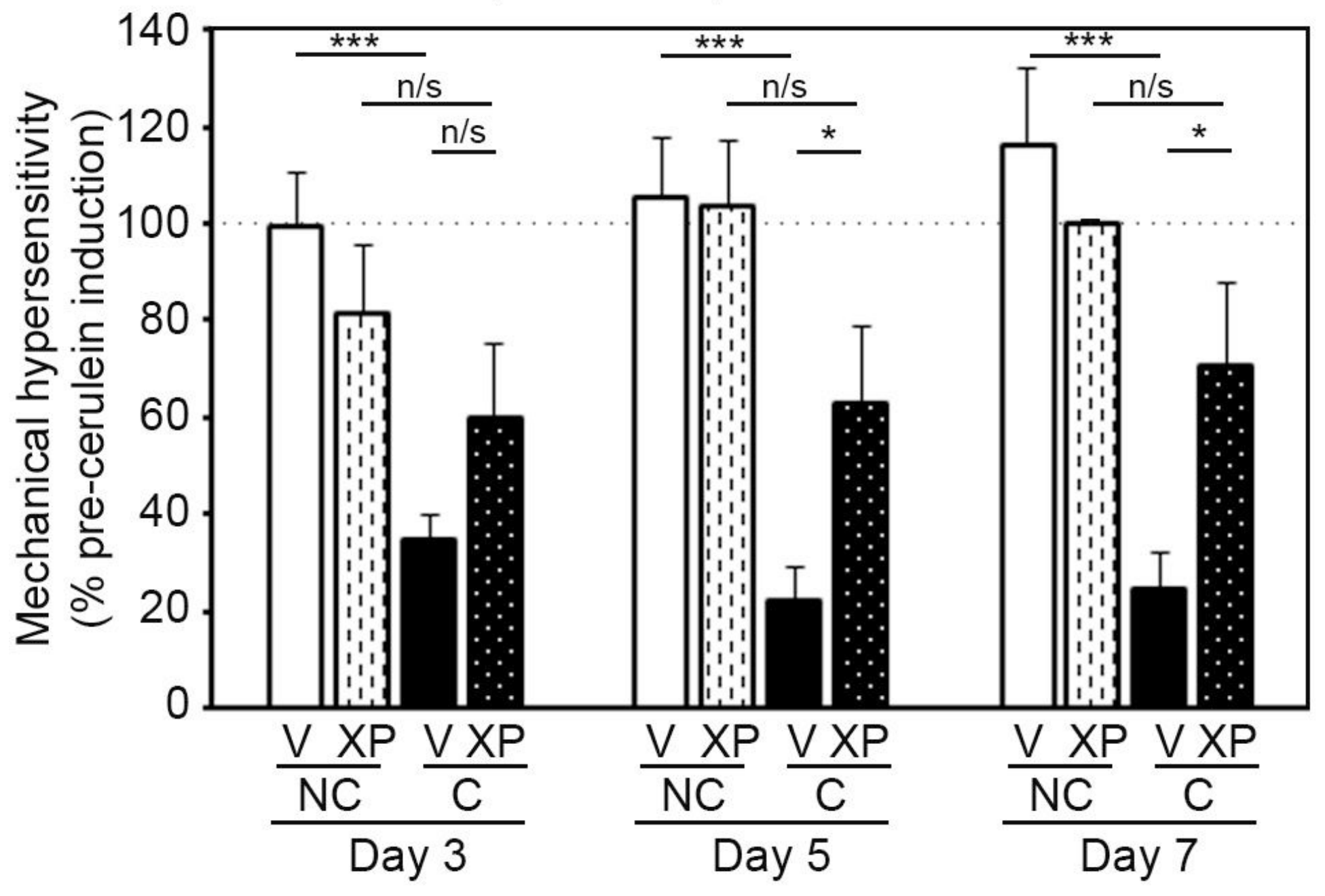

Figure 4

Soluble TNF activity reduces hindpaw mechanical hyper-sensitivity following induction of acute pancreatitis in mice. Graph shows mechanical hypersensitivity of the hindpaw when touched by von Frey filaments, as a percentage of pre-cerulein baseline data for each mouse. No differences were observed in hypersensitivity of non-pancreatitis mice between baseline and on days 3,5 and 7 , independent of treatment ( $n=6-8)$. In contrast, vehicle-treated pancreatitis mice displayed significantly more hypersensitivity than non-pancreatitis control mice at each time point assessed during the first week $(n=9)$. Treating mice with XPro1595 prevented this hypersensitivity at all time-points tested $(n=9)$, and this group displayed significantly less hypersensitivity than the vehicle-treated pancreatitis group on the last 2 days of testing. $\mathrm{NC}=$ non-cerulein, $\mathrm{C}=$ cerulein, $\mathrm{V}=$ vehicle, $\mathrm{XP}=\mathrm{XPro1595},{ }^{*} \mathrm{p}<0.05,640 * * * \mathrm{p}<0.001$. 

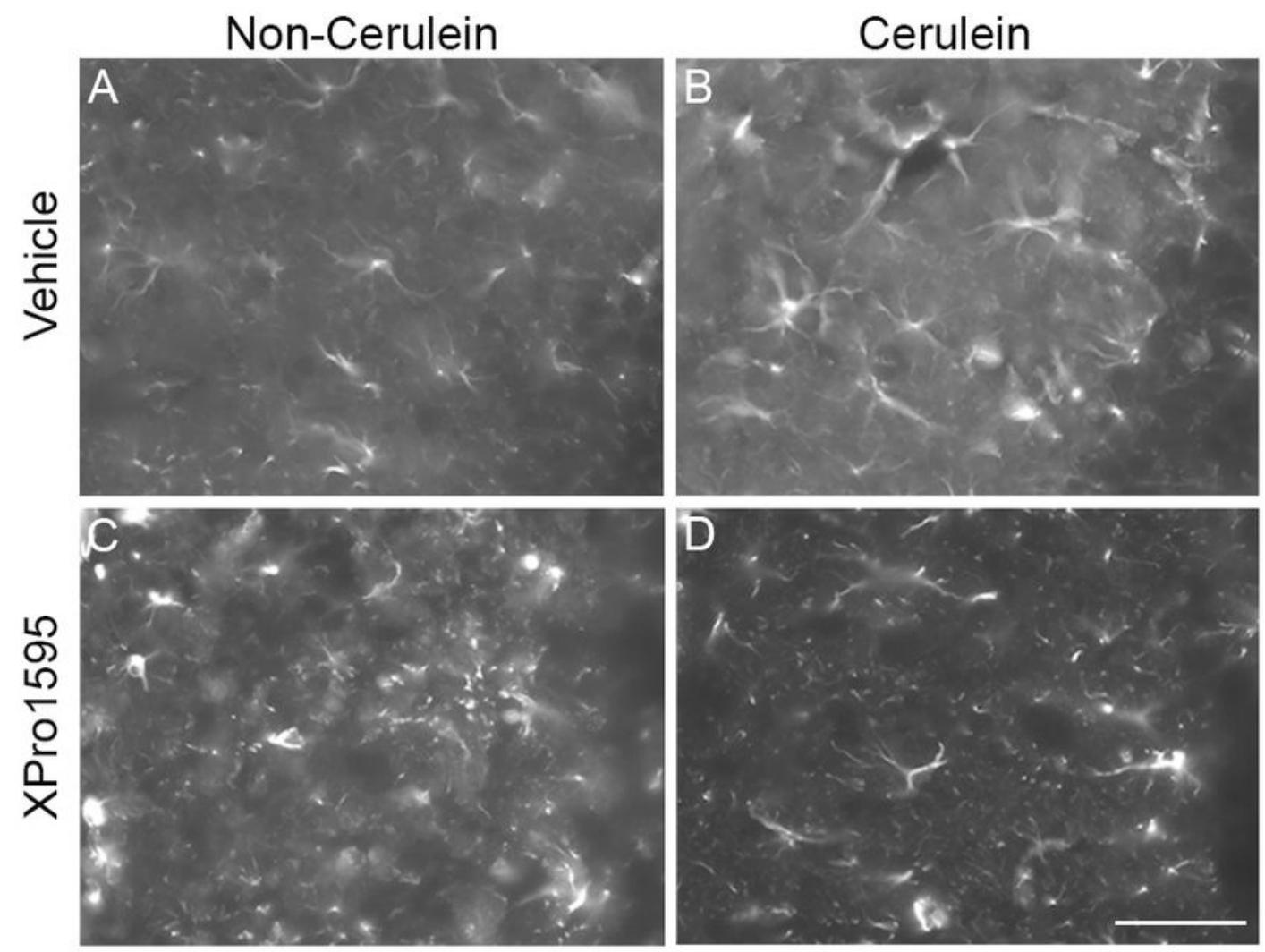

$E$

Hippocampal Astrocytic Reactivity

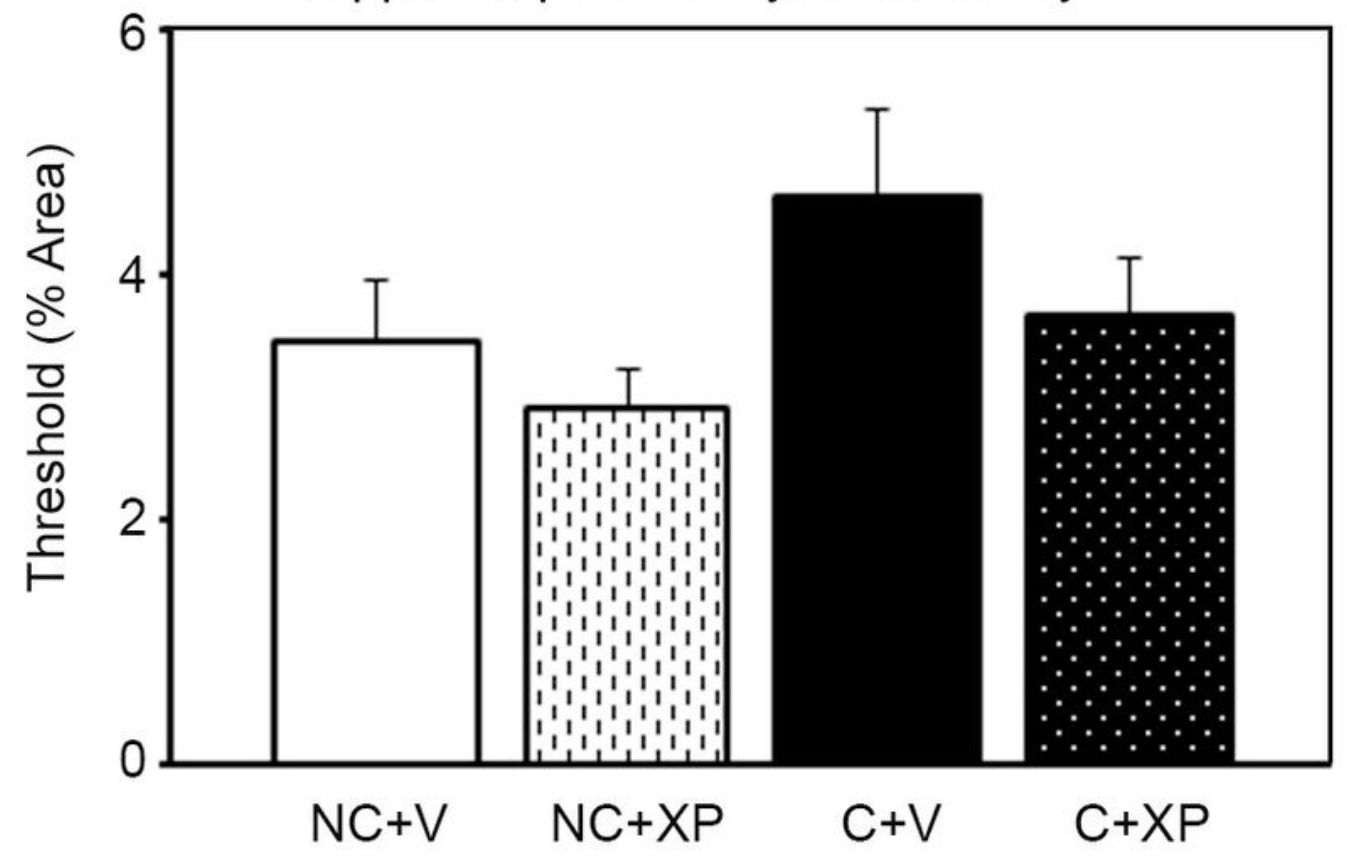

Figure 5

Hippocampal GFAP expression is more pronounced in cerulein-treated mice without XPro1595 administration. CA1 hippocampal GFAP expression was semi-quantitated 7 days following induction of pancreatitis in mice. Non-pancreatitis mouse groups, independent of vehicle or XPro1595 treatment, did not display reactive astrogliosis (A\&C) ( $n=3-4)$. In contrast, the vehicle-treated pancreatitis tissue (B) had numerous reactive astrocytes and when quantitated displayed a tendency for increased GFAP expression 
$(n=4)$, compared to the non-pancreatitis groups, but was not statistically significantly different (E). XPro1595 treated pancreatitis mice prevented the induction of reactive astrocytes $(D)(n=4)$. NC = noncerulein, $\mathrm{C}=$ cerulein, $\mathrm{V}=$ vehicle, $\mathrm{XP}=\mathrm{XPro1595}$, scalebar $=100 \mu \mathrm{m}$. 